\title{
Subacute effects of the number of Pilates exercise series on cardiovascular responses in hypertensive women
}

\author{
Jocarla C Chagas $^{1}$ (1) , Rodrigo Miguel-dos-Santos ${ }^{1,2,3}$ (D) , Afrânio A Bastos ${ }^{1}$ (1) , Evaleide D Oliveira ${ }^{1,4}$ (i) , \\ Valter J Santana-Filho ${ }^{3,4}$ (D) , Rogério B Wichi ${ }^{1}$ \\ ${ }^{1}$ Universidade Federal de Sergipe, Departamento de Educação Física, Núcleo de Pós-graduação em Educação \\ Física, São Cristóvão, SE, Brasil; ${ }^{2}$ Norwegian University of Science and Technology, Faculty of Medicine and \\ Health Sciences, Department of Circulation and Medical Imaging, Cardiac Exercise Research Group, Trondheim, Norway; \\ ${ }^{3}$ Universidade Federal de Sergipe, Departamento de Fisiologia, Núcleo de Pós-graduação em Ciências Fisiológicas, São \\ Cristóvão, SE, Brasil; ${ }^{4}$ Universidade Federal de Sergipe, Departamento de Fisioterapia, São Cristóvão, SE, Brasil
}

\begin{abstract}
Aim: To evaluate the subacute effects of the number of Pilates exercise series (one and three) on the cardiovascular responses of medicated hypertensive women. Methods: Eight hypertensive and nine normotensive women underwent a Pilates session with low and high volume, and cardiovascular responses were measured. Aged sample of 50-65 years old underwent to anthropometrical measurements previously to the experimental procedures. The cardiovascular assessment was performed before and after every experimental session. The experimental procedures consisted of two familiarization sessions, load determination, and two experimental sessions (one or three series) for each group. Results: In the intragroup analysis, HR was found to be reduced in the normotensive group. In the hypertensive group, a reduction in the double product was observed after both Pilates sessions, and in the normotensive group only after the session with one series. The volume of exercises of the Pilates method did not interfere in the responses of systolic and diastolic BP after exercise. However, a more prominent area under the curve was seen in the systolic BP of hypertensive subjects who performed three series. Conclusion: The present study shows that performing one or three series of the Pilates exercise does not induce hypotension post-exercise and did not interfere in the cardiovascular responses of medicated hypertensive women.
\end{abstract}

Keywords: hemodynamic parameters, hypertension, postmenopausal women, strength exercise, exercise variables.

\section{Introduction}

Hypertension, a multifactorial clinical condition characterized by high and sustained blood pressure levels (systolic pressure $\geq 140 \mathrm{mmHg}$ or diastolic pressure $\geq 90 \mathrm{mmHg})^{1}$, is the most important risk factor for ischemic heart disease and stroke. Despite the growing body of research trying to find a treatment for hypertension, it has not yet been possible to find a treatment that covers a large part of this population.

Most up to date Brazilian Society of Cardiology and Hypertension $^{2}$, the American Heart Association (AHA)/American College of Cardiology (ACC) and the task force workgroup ${ }^{3}$, the most recent AHA/ACC Scientific Statement ${ }^{4}$, the American College of Sports Medicine (ACSM) ${ }^{5}$, and the European Society of Hypertension and European Society of Cardiology ${ }^{6}$ guidelines recommend resistance exercise (RE) as a potential complement in the treatment of hypertension associated or not to aerobic exercise programs. Taking into account that strength training involves muscle contraction against an opposite resistance exerted by weights, elastic bands, or equipments ${ }^{7}$, Pilates is also a strength training method. Pilates is a method that trains the whole body, involving isotonic and isometric contractions, which uses spring elastic resistance to offer opposing force or assistance in performing the exercises ${ }^{8,9}$. Movements are coordinated by breathing, emphasizing the abdominal muscles ${ }^{10,11}$. Moreover, it is based on six principles (concentration, control, center, fluidity, precision, and breathing), which provide a better execution of exercises and more effective results ${ }^{12}$.

Taking into account the diverse methodology used for Pilates professionals, it can be seen that there is no scientific evidence on standardization of the Pilates training protocol regarding intensity, workload, the number of repetitions, recovery interval, as well as number of sets. These variables are essential factors that interfere with the cardiovascular responses and become even more critical when dealing with hypertensive patients ${ }^{13-15}$.

In recent years, there has been an increase in the number of Pilates practitioners in several countries ${ }^{16}$, and it is necessary to develop researches investigating its benefits. Some studies have already investigated the effect of the Pilates method on cardiovascular responses, demonstrating the efficacy of its effect on lowering BP in normotensive ${ }^{17,18}$ and hypertensive populations ${ }^{19-21}$. Nonetheless, these studies present gaps regarding training variables that must be used in the sessions ${ }^{22}$. Thus, the objective of this study was to evaluate the subacute effects of the number of Pilates exercise series (one and three) on the cardiovascular responses of medicated hypertensive women. 


\section{Methods}

The study was approved by the Research Ethics Committee of the Federal University of Sergipe (CAEE: 48580215.9.0000.5546). All participants signed the Free and Informed Consent Form in accordance with the recommendations of Resolution 466/2012 of the National Health Council.

\section{Sample}

Forty-two volunteers were enrolled in the study, being allocated in the normotensive $(n=23)$ or treated hypertensive $(n=19)$ based on medical diagnosis. The inclusion criteria were being women aged 50-65 years, hypertension with a clinical diagnosis and underwent antihypertensive therapy, reported absence of menses for at least one year without hormone replacement, non-physically active, without cardiometabolic diseases and health problems that made it impossible to perform the exercises and body mass index $(\mathrm{BMI})<30 \mathrm{~kg} / \mathrm{m}^{2}$. The exclusion criteria were: perform vigorous physical activity during the experimental period, change of medication, SBP, and DBP greater than 130 and $85 \mathrm{mmHg}$, respectively, before experimental sessions, inability to complete the exercises, and not attending all the stages of the experimental protocol.

Forty-two women signed up to participate in the study. Of these, 25 women were excluded: three because they had diabetes, four because they were obese, three for making use of beta-blockers, five for being physically active, and 10 for not completing the training protocol. Thus, the final sample of the study was 17 sedentary postmenopausal women, of whom eight were hypertensive with blood pressure controlled by medication (experimental group), and nine were normotensive (control group). The sample size was defined by convenience. The use of antihypertensive treatment and the pharmacological class of drugs were verified by reviewing the prescriptions written by clinicians. The antihypertensive classes used were angiotensin II receptor antagonists (Aradois, 12.5\%; and Losartan, 87.5\%), diuretics (Higotron, 11.1\%; and Hydrochlorothiazide, 25\%) and calcium channel blockers (Amlodipine besylate, 12.5\%).

\section{Data collection procedures}

\section{Anthropometry}

The body mass was measured by a digital scale with an accuracy of $100 \mathrm{~g}$. The height was measured using a stadiometer, being evaluated without footwear and with feet attached, the posterior surfaces of the heels, pelvic girdle, shoulder girdle, and occipital region being in contact with the measurement scale $^{23}$. Measurements of the waist and hip circumferences were performed using a flexible, and non-extensible anthropometric tape with a scale of $0.1 \mathrm{~cm}$. The waist-hip ratio (WHR) was obtained from the waist and hip circumference values ${ }^{24}$.

\section{Cardiovascular responses}

Heart rate (HR) was measured using an HR monitor (Polar ${ }^{\circledR}$ RS800, FI-90440 KEMPELE, Finland). The measurements of systolic and diastolic BP(SBP and DBP, respectively) were performed by an automatic digital arm pressure monitor (Microlife $\AA$ - BP 3BTO-A, Switzerland), and following the VII Brazilian Guidelines for Hypertension ${ }^{1}$, in which the evaluated patient remained seated, with the legs uncrossed and resting for 10 minutes before starting the procedure. The arm was at the midpoint of the sternum or fourth intercostal space, with the palm facing upwards and the elbow slightly flexed. The double product (DP) was obtained by multiplying SBP by HR.

In order to obtain the arithmetic mean of the rest values of each variable, $\mathrm{BP}$ and $\mathrm{HR}$ were monitored for 20 minutes, measuring every five minutes, before the exercise session. At the end of each session, the participants remained resting, seated, and the 60-minute monitoring was started, measuring the BP and HR every 15 minutes.

\section{Familiarization sessions}

There were two familiarization sessions to the exercise protocol of the Pilates method, with a 48-hour interval between sessions ${ }^{25,26}$. The familiarization sessions were done to teach the technique of the exercises, preventing execution errors during the experimental sessions.

Determination of the loads used in the experimental sessions

After familiarization sessions, it was performed two tests to determine the load used in the experimental sessions for each exercise. The intensity of the exercises was estimated by the subjective perception of effort using the OMNI-RES scale 27,28 in a mimetic one repetition maximum (1RM) test. Each participant was asked to point out on the scale their perceived effort immediately after the end of each attempt, which should correspond to the moderate intensity ( 5 to 7 ). Springs were added or removed, when necessary, to the apparatus until it reached moderate intensity. The load was determined at most in three attempts, with a three-minute recovery interval between them.

\section{Experimental sessions}

Each participant performed both experimental sessions (one or three series), for which they were randomly assigned (https://www. randomizer.org/) to which session would be held first. Thus, they had two sessions of Pilates exercises with different numbers of sets (one or three), with a one-week interval between them, always in the morning and with controlled room temperature $\left(\sim 24^{\circ} \mathrm{C}\right)$. The exercise protocol was easy to perform and was based on professional practice, in which strength and dynamic stretching exercises are used in the same session.

The protocol consisted of 15 exercises, containing exercises of strength and dynamic stretching. The warmup was performed with five exercises of solo (knee drop, corcel, pelvic curl, the hundred, half roll down-additional information provided in the Supplemental Methods) without rest interval between exercises. Moreover, ten 
exercises were performed on specific equipment under spring resistance, with 10 repetitions and a one-minute interval between sets (footwork on the reformer, footwork tendon stretch on the cadillac, side split, sit up, swan, arm spring-triceps, arm spring-biceps, down stretch, mermaid, hamstring - additional information provided in the Supplemental Methods). The exercises were performed in the order in which they were cited. Exercise intensity was controlled using the OMNI-RES Scale, such as previously described, with each participant rating the perceived effort immediately after each set, and the load was adjusted as needed to maintain the moderate intensity.

The exercises were performed with the maintenance of the axial elongation and neutral column, preserving its natural curvatures. The participants had a constant incentive for the respiration to be diaphragmatic and associated to the intercostal, valuing expiration, during the pushups or at the time of the most considerable effort and synchronized to the exercise.

\section{Statistical analysis}

Data were presented as mean and standard deviation. The Shapiro-Wilk test verified the normality of the data. From this test, it was identified that the data followed a normal distribution. The Student t-test for unpaired samples was used to verify the difference between the anthropometric and hemodynamic variables of the groups in the resting. The comparison between the mean values of SBP, DBP, HR, and DP of the groups was performed by two-way analysis of variance (ANOVA) with repeated measures to analyze the intragroup differences and ordinary two-way ANOVA to analyze intergroup differences, followed by the Bonferroni post-test. The level of significance was set at $p<0.05$. The analyses were performed using GraphPad Prism software in version 8.

\section{Results}

The anthropometric and hemodynamic characteristics (SBP, DBP, HR, and DP) of the sample are shown in Table 1. There was no difference between baseline values of hemodynamic and anthropometric variables of evaluated groups.

Intergroup analysis showed that three series of Pilates induced an increase of SBP in hypertensive subjects compared to normotensive who performed one series immediately after the exercise session $(128 \pm 6 \mathrm{mmHg}$ vs. $113 \pm 12 \mathrm{mmHg}$, respectively; $p=0.03$; Figure 1 ). In addition, the number of series did not interfere in the DBP, HR, and DP responses.

In the intragroup analysis, it was observed reduction in SBP 15 (one set: $116 \pm 8 \mathrm{mmHg}, \mathrm{p}=0.03$; three sets: $116 \pm 10 \mathrm{mmHg}$, $\mathrm{p}=0.0004$ ) and 30 minutes (one set: $109 \pm 9 \mathrm{mmHg}, \mathrm{p}<0.0001$; three sets: $118 \pm 6 \mathrm{mmHg}, \mathrm{p}=0.0074)$ after exercise compared to the moment immediately after the exercise (one set: $125 \pm 11$ $\mathrm{mmHg}$; three sets: $128 \pm 6 \mathrm{mmHg}$ ) in hypertensive subjects. This reduction was also prolonged until 45 minutes when the hypertensive subjects performed one set $(111 \pm 9 \mathrm{mmHg}, \mathrm{p}<0.0001)$, albeit it has occurred an increase of 60 minutes after exercise $(119 \pm 9 \mathrm{mmHg}, \mathrm{p}<0.0001)$ compared to 30 minutes. Despite the reduction of $6.5 \%$ seen in the hypertensive group 30 minutes after performing one set of Pilates $(\mathrm{p}=0.1259)$, reaching similar SBP values compared to normotensive group (one set: $109 \pm 13$ $\mathrm{mmHg}$; three sets: $111 \pm 13 \mathrm{mmHg}$ ), none significant statistical difference was observed compared to rest $(117 \pm 9 \mathrm{mmHg})$.

The hypertensive group also had an accentuated increase in DBP after the Pilates session performed with three series $(82 \pm 8$ $\mathrm{mmHg}$; $=0.02)$ compared with the rest $(74 \pm 5 \mathrm{mmHg}$; Figure 2$)$. However, the DBP reduced after $15 \mathrm{~min}(75 \pm 7 \mathrm{mmHg}$; $\mathrm{p}=0.04)$, returning to rest values. There was also a significant reduction 30 minutes after exercise in DBP of the hypertensive subjects underwent to one set $(70 \pm 10 \mathrm{mmHg} ; \mathrm{p}=0.02)$ compared to the moment immediately after exercise $(78 \pm 7 \mathrm{mmHg})$.

We have further analyzed systolic and diastolic BP calculating the area under the curve (AUC) over an hour after exercise. Our analysis revealed a bigger AUC of SBP in the hypertensive group when performed three series (604 \pm 13 vs. one set: 578 $\pm 15 \mathrm{mmHg}, \mathrm{p}=0.02$; Figure 3 ). AUC was also more prominent compared to normotensive when performed both one $(557 \pm 18$ $\mathrm{mmHg}, \mathrm{p}<0.0001)$ and three series $(571 \pm 22 \mathrm{mmHg}, \mathrm{p}=0.002)$.

Furthermore, an HR reduction in the control group was observed when Pilates session was performed with one series, at all moments after exercise ( 0 min: $79 \pm 7 \mathrm{bpm}, \mathrm{p}=0.001 ; 15 \mathrm{~min}$ : $80 \pm 6$ bpm, $p=0.02 ; 30 \mathrm{~min}: 77 \pm 4$ bpm, $p=0.0001 ; 45 \mathrm{~min}: 77$ $\pm 5 \mathrm{bpm}, \mathrm{p}<0.0001 ; 60 \mathrm{~min}: 79 \pm 5 \mathrm{bpm}, \mathrm{p}=0.006)$, compared to rest ( $86 \pm 7 \mathrm{bpm}$; Figure 4$)$. The normotensive subjects also had a considerable reduction immediately after they perform one series $(p=0.02)$ compared with the session that they completed three series $(86 \pm 4 \mathrm{bpm})$. While in the control group that performed the Pilates session with three series, HR reduction was observed in relation to pre-exercise moment $(85 \pm 5 \mathrm{bpm})$ only after 60 minutes of recovery $(77 \pm 6 \mathrm{bpm}, \mathrm{p}=0.003)$ that was also lower compared to the moment immediately after exercise (86 \pm 4 bpm, $\mathrm{p}<0.0001)$ and 15 minutes $(83 \pm 6 \mathrm{bpm}, \mathrm{p}=0.04)$.

This also occurred with the hypertensive group when performed Pilates session with one series, showing a reduction in HR 60 minutes after exercise $(75 \pm 10 \mathrm{bpm}, \mathrm{p}=0.003)$ in comparison to rest $(82 \pm 10 \mathrm{bpm})$. After the highest volume in the Pilates session, HR reduction was observed only after 30 minutes (73 \pm 9 bpm vs. rest: $80 \pm 8$ bpm, $\mathrm{p}=0.003)$. Nonetheless, the hypertensive group showed reduction in HR compared to the moment after exercise (three sets: $83 \pm 7 \mathrm{bpm}$; one set: $83 \pm 11$ bpm) starting at 15 minutes ( 15 min: $76 \pm 9$ bpm, $p=0.009 ; 30$ min: $73 \pm 9$ bpm, $p=0.0001 ; 45 \min : 76 \pm 8$ bpm, $p=0.01 ; 60$ min: $74 \pm 7 \mathrm{bpm}, \mathrm{p}=0.0007)$ when executed three series and from $30 \mathrm{~min}(30 \mathrm{~min}: 77 \pm 9 \mathrm{bpm}, \mathrm{p}=0.03 ; 45 \mathrm{~min}: 76 \pm 9 \mathrm{bpm}$, $\mathrm{p}=0.02 ; 60 \mathrm{~min}: 75 \pm 10 \mathrm{bpm}, \mathrm{p}=0.004)$ when executed one series.

It can also be seen that three series induced an increase of DP in the normotensive group immediately after exercise (10149 $\pm 1430 \mathrm{mmHg}$ x bpm, $\mathrm{p}=0.03)$ compared to one series $(8935 \pm$ $1577 \mathrm{mmHg}$ x bpm; Figure 5). Besides, the hypertensive group had a reduction in the DP after Pilates session with one series, at $30(8357 \pm 1098 \mathrm{mmHg} \times \mathrm{bpm}, \mathrm{p}=0.003)$ and 45 minutes $(8465$ $\pm 986 \mathrm{mmHg} \times \mathrm{bpm}, \mathrm{p}=0.01)$ post-exercise recovery, and in the normotensive ( 1 series) and hypertensive ( 3 series) groups only 30 minutes $(8453 \pm 1233 \mathrm{mmHg} \times \mathrm{bpm}, \mathrm{p}=0.003 ; 8641 \pm 944$ $\mathrm{mmHg} \times \mathrm{bpm}, \mathrm{p}=0.02$, respectively) after the Pilates session, compared to the pre-exercise moment (Normotensive - one 
set: $9624 \pm 1036$ mmHg x bpm; Hypertensive - one set: 9604 \pm 1512 mmHg x bpm; Hypertensive - three sets: $9735 \pm 1461$ mmHg x bpm).

The hypertensive subjects had lower values of DP at all moments (one set - 15 min: $9394 \pm 1243 \mathrm{mmHg} x$ bpm, $\mathrm{p}=0.04$; $30 \mathrm{~min}$ : 8357 $\pm 1098 \mathrm{mmHg} x \mathrm{bpm}, \mathrm{p}<0.0001 ; 45 \mathrm{~min}: 8465 \pm 986 \mathrm{mmHg}$ x bpm, p <0.0001; 60 min: $8971 \pm 1346 \mathrm{mmHg} \times \mathrm{bpm}, \mathrm{p}=0.0004$; three sets - 15 min: $9017 \pm 1547 \mathrm{mmHg} \times \mathrm{bpm}, \mathrm{p}=0.002$; $30 \mathrm{~min}: 8641 \pm$
$944 \mathrm{mmHg}$ x bpm, $\mathrm{p}<0.0001$; $45 \mathrm{~min}: 9225 \pm 1416 \mathrm{mmHg}$ x bpm, $\mathrm{p}=0.02$; $60 \mathrm{~min}: 9121 \pm 1069 \mathrm{mmHg} \times \mathrm{bpm}, \mathrm{p}=0.005$ ) compared to the moment immediately after the exercise in both Pilates sessions (one series: $10393 \pm 1745 \mathrm{mmHg}$ x bpm; three series: $10318 \pm 1602$ $\mathrm{mmHg}$ x bpm). While the normotensive group showed this same response only after $30(9005 \pm 968 \mathrm{mmHg}$ x bpm vs. $0 \mathrm{~min}: 9461 \pm$ $1379 \mathrm{mmHg} \times \mathrm{bpm}, \mathrm{p}=0.004)$ and 60 minutes $(9002 \pm 822 \mathrm{mmHg}$ $\mathrm{x}$ bpm, $\mathrm{p}=0.004$ ) when executed three series.

Table 1 - Anthropometric and hemodynamic characteristics of the sample.

Normotensive

(9)

\begin{tabular}{lcc}
\hline Age (years) & $57 \pm 5.0$ & $59 \pm 5.1$ \\
Body mass (kg) & $65 \pm 6.8$ & $63 \pm 8.9$ \\
Height (m) & $1.57 \pm 0.1$ & $1.53 \pm 0.1$ \\
BMI $\left(\mathrm{kg} / \mathrm{m}^{2}\right)$ & $27 \pm 3.6$ & $26 \pm 3.0$ \\
WHR & $0.84 \pm 0.1$ & $0.89 \pm 0.1$ \\
SBP $(\mathrm{mmHg})$ & $111 \pm 10$ & $118 \pm 10$ \\
DBP $(\mathrm{mmHg})$ & $77 \pm 7$ & $73 \pm 6$ \\
HR $(\mathrm{bpm})$ & $87 \pm 7$ & $80 \pm 11$ \\
DP $(\mathrm{bpm} x \mathrm{mmHg})$ & $9624 \pm 1036$ & $9507 \pm 1444$ \\
\hline
\end{tabular}

Values represented as mean \pm standard deviation. BMI: body mass index; WHR: waist-hip ratio; SBP: systolic blood pressure; DBP: diastolic blood pressure; HR: heart rate; DP: double product. Student t-test for unpaired samples.

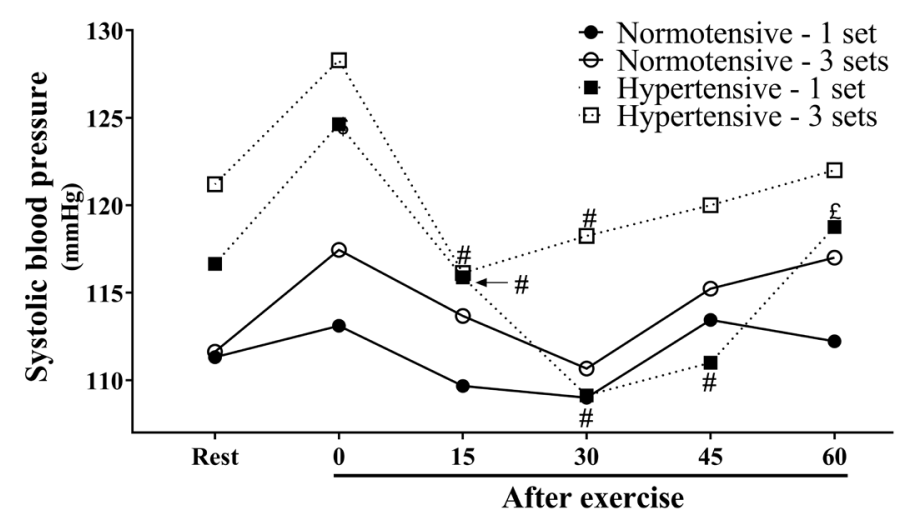

Figure 1 - Response of systolic blood pressure to different volumes of exercises (1 or 3 series) of the Pilates method. Two-way ANOVA followed by the Bonferroni post-test. $\$: \mathrm{p} \leq 0.05$ vs. Normotensive $1 \mathrm{set} ; \#: \mathrm{p} \leq 0.05$ vs. $0 \mathrm{~min}, £: \mathrm{p} \leq 0.05$ vs. $30 \mathrm{~min}$ in the same group.

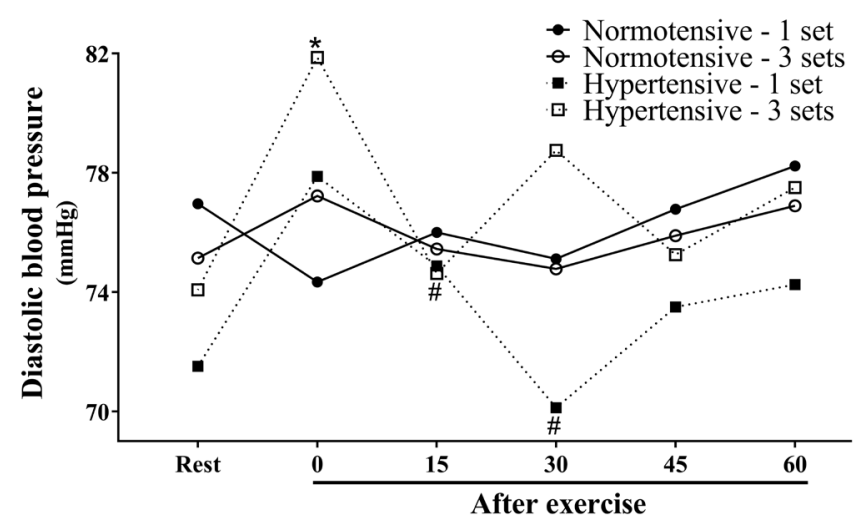

Figure 2 - Response of diastolic blood pressure to different volumes of exercises ( 1 or 3 series) of the Pilates method. Two-way ANOVA followed by the Bonferroni post-test. $*: \mathrm{p} \leq 0.05$ vs. rest, \#: $\mathrm{p} \leq 0.05$ vs. 0 min in the same group. 

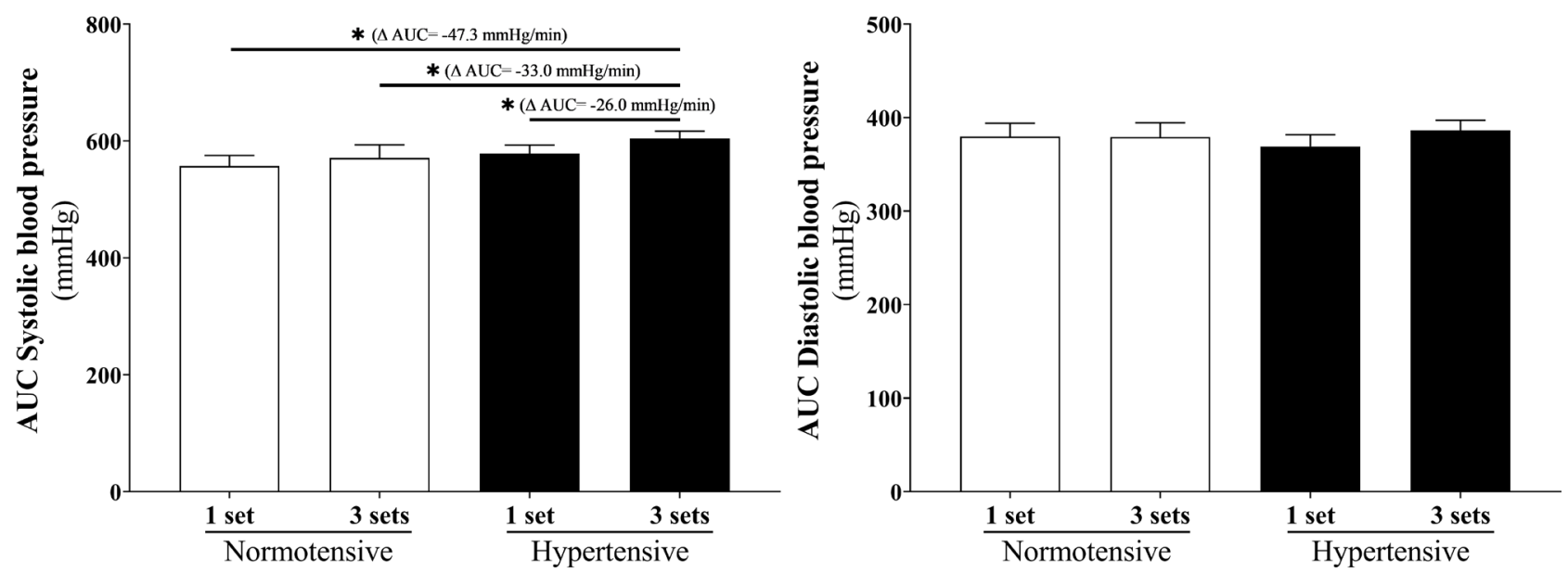

Figure 3 - Area under the curve of systolic blood pressure response to different volumes of exercises (1 or 3 series) of the Pilates method. One-way ANOVA followed by the Bonferroni post-test.

$*: \mathrm{p} \leq 0.05$

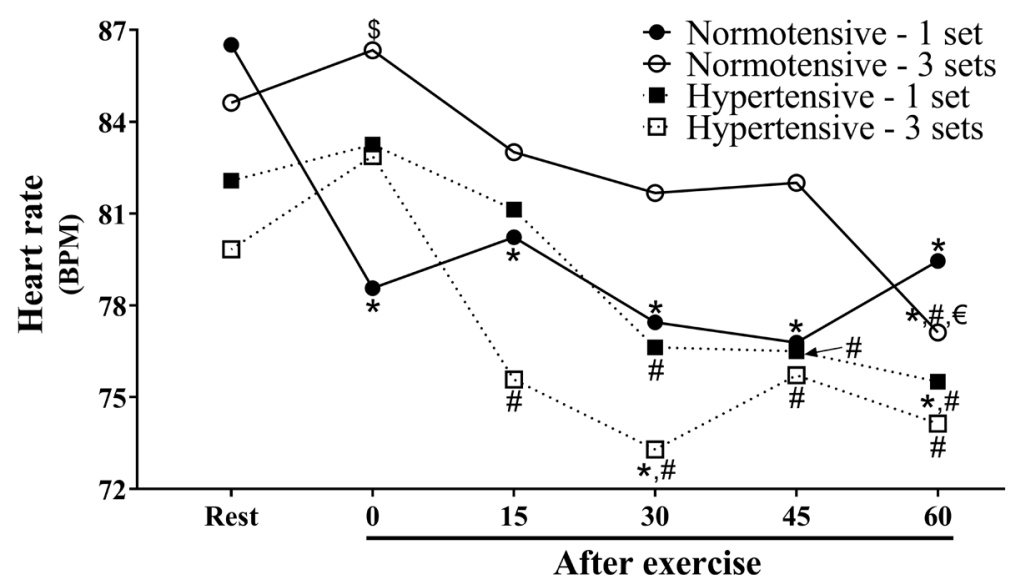

Figure 4 - Heart rate response to different exercise volumes of exercises (1 or 3 sets) of the Pilates method. Two-way ANOVA followed by the Bonferroni posttest.

$\$: \mathrm{p} \leq 0.05$ vs. Normotensive 1 set; $*: \mathrm{p} \leq 0.05$ vs. rest, $\#: \mathrm{p} \leq 0.05$ vs. 0 min, $€: \mathrm{p} \leq 0.05$ vs. $15 \min$ in the same group.

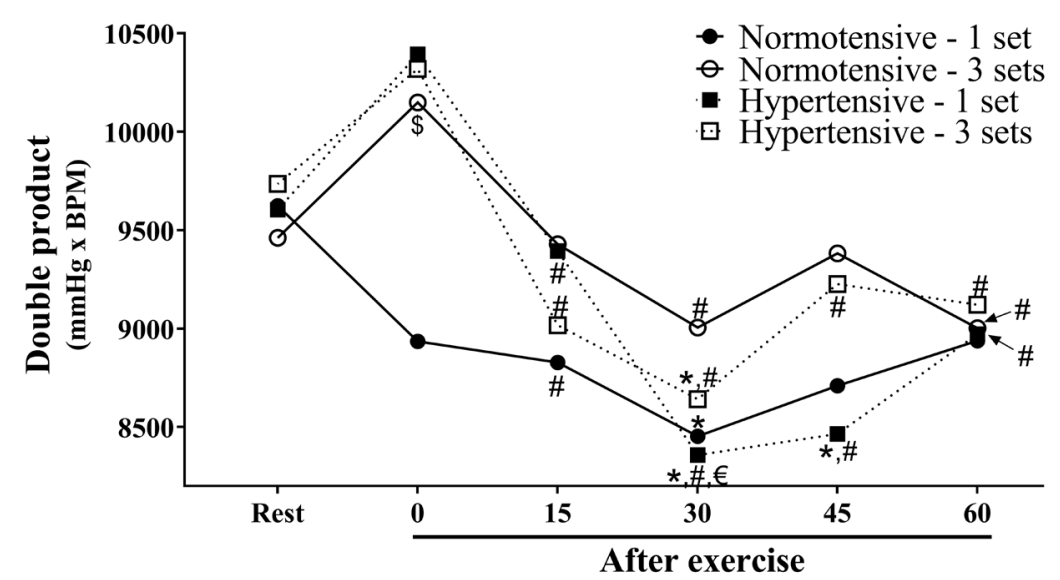

Figure 5 - Response of the double product to different volumes of exercises (1 or 3 series) of the Pilates method. Two-way ANOVA followed by the Bonferroni post-test.

$\$: \mathrm{p} \leq 0.05$ vs. Normotensive 1 set; *: $\mathrm{p} \leq 0.05$ vs. rest, $\#: \mathrm{p} \leq 0.05$ vs. 0 min, $€: \mathrm{p} \leq 0.05$ vs. $15 \min$ in the same group. 


\section{Discussion}

The objective of this study was to evaluate the subacute effect of the number of Pilates exercises series (one and three) on the cardiovascular responses of hypertensive women. The main findings of this study showed that the number of Pilates exercises series did not induce hypotension post-exercise in medicated hypertensive women, as well as did not evoke exacerbation in the cardiovascular responses, proving the safety in a hypertensive population with pharmacologically controlled blood pressure.

Most of the studies found in the literature that evaluated the strength exercise variables use the test of 1RM or 10RM. In the present study, we used the subjective perception of effort through the OMNI-RES scale ${ }^{27,28}$, which is reproducible in a sedentary population and in elderly women ${ }^{29}$ to determine the $1 \mathrm{RM}$ load and the intensity used in the experimental sessions. This scale is an instrument of easy application and low cost that has been widely used and validated to indicate a perceived effort to strengthen exercise ${ }^{28,30}$.

Regarding the BP measurement, the oscillometric technique used in this study is recommended for clinical use in the adult population ${ }^{31}$. Also, it is equivalent to the auscultatory technique when evaluating pre- and post-exercise values ${ }^{32}$. The basal hemodynamic variables of SBP, DBP, HR, and DP were similar between the hypertensive and normotensive groups. All hypertensive subjects were found to have normal blood pressure values due to the use of medication. This factor may have influenced the outcome and maybe an explanation for the absence of post-exercise hypotension since the hypotensive effect of exercise is greater in individuals with higher $\mathrm{BP}^{33}$. Despite this, Cunha and Jardim ${ }^{34}$ evaluated post-exercise hypotension using the oscillometric technique to measure BP up to 60 minutes after the strength exercise sessions, with three sets of seven to $10 \mathrm{RM}$ and two-minute rest interval in the elderly hypertensive patients treated pharmacologically. However, the result was similar to our study because they did not verify changes in SBP or DBP immediately after exercise.

Canuto, et al..$^{35}$ compared the effect of two exercise sessions, of which one was composed of two sets of 16 repetitions with half of the 8RM load and the other consisting of two sets of eight repetitions with an $8 \mathrm{RM}$ load in 32 hypertensives medicated women. Similar to the present study, but using the auscultatory technique for BP measurement, they did not verify post-exercise hypotension in the groups that performed the session with light or high intensity.

Most recently, Rocha, Cunha, Cordeiro, et al. ${ }^{20}$ showed a remarkable SBP reduction of $8 \mathrm{mmHg}$ after a Pilates session in middle-aged adults with hypertension. They assessed the effects of a Pilates session performed with a single set of 10 repetitions at moderate intensity ( 3 to 5 points in the OMNI-RES scale) and the Pilates session comprised of 16 exercises. Nevertheless, Batista, et al. ${ }^{18}$ also did not find BP reduction in 16 normotensive postmenopausal women that performed 10 mat Pilates exercises although there has been an increase in nitrite concentrations in saliva 60 minutes after the exercise session.

The absence of hypotension after the sessions with one or three series of Pilates exercises in our study may also be related to the nature of the exercises that were performed at the end of the sessions, consisting of stretching exercises. Since the dynamic and active stretching under spring resistance was inserted into the protocol, considering that this type of stretching is usually part of the exercise routine in the Pilates sessions. No studies were found to evaluate the effect of this type of exercise on cardiovascular responses in middle-aged or senior women. Although Lima, et al. $^{36}$ had evaluated the effect of passive stretching only on the cardiovascular responses of male subjects with the noninvasive technique of continuous measurements of beat-to-beat BP, using photoplethysmography (Finometer PRO, Finapress $\left.{ }^{\circledR}\right)$, they found no changes in arterial pressure after exertion.

Interestingly, Rocha, et al. ${ }^{20}$ did not include stretching exercises at the end of the Pilates session, and, as mentioned earlier, showed remarkable post-exercise hypotension. It is worth noting that both in the Rocha, et al. ${ }^{20}$ study and in our study, blood pressure was monitored for only 60 minutes after the exercise session and that this response may be different after this period, regardless of the use or not of stretching exercises in the session.

Regarding the influence of training volume on cardiovascular responses, our study differs from most literature findings ${ }^{37,38}$, which generally associate the largest volume (number of series) with the promotion of more significant post-exercise hypotensive effects. Scher, et al. ${ }^{39}$ evaluated the subacute effect of different volumes of low-intensity strength exercises on the magnitude and extent of BP changes in 16 elderly (seven men and nine women) hypertensive subjects treated. Different from our study, the authors verified, through the auscultatory method, that both exercise sessions promoted BP reduction 60 minutes after exercise. However, only the largest exercise session promoted a reduction of over 24 hours.

Brito, Oliveira CVC, Brasileiro-Santos, et al. ${ }^{37}$ evaluated the effect of two sessions with ten strength exercises at $50 \%$ of $1 \mathrm{RM}$ with different volumes (one or three series) on the post-exercise hypotension of 10 elderly hypertensive subjects ( six women and four men) physically active, using the noninvasive technique of continuous measures of beat-to-beat BP. The authors observed that the high-volume exercise (three series) promoted greater hypotension.

The difference in the level of training of individuals compared to our study may also have influenced the outcome since trained subjects tend to bear higher loads than sedentary individuals with an equal perception of effort ${ }^{38}$. Mediano, et al. ${ }^{40}$ tested the effect of two strength exercise sessions performed with different volume (one and three series) on the blood pressure of 16 men and four women with drug-controlled hypertension. Blood pressure was measured using an aneroid sphygmomanometer immediately after the end of each session and for 60 minutes after and found a reduction of SBP only 40 minutes later, but there was no change in DBP when the participants performed the session with a set of exercises. After the three series session, DBP was reduced at 30 and 50 minutes post-exercise and SBP during the whole monitoring period. Differing from the findings of this study, they 
demonstrated that the largest volume session (three series) promoted changes in BP for a longer time. The higher volume resulted in higher effort perception, and this factor may have determined the results.

Regarding HR response, a reduction of this variable was observed in all groups compared to basal values, regardless of the number of sets. However, just in the control group, when the Pilates session was performed with one series, HR reduction was observed in all post-exercise recovery moments. The reduction of HR in our study may be related to controlled breathing, characteristic of Pilates, which promotes greater activation of the parasympathetic nervous system by reducing HR. Although the study by Rodrigues et al. ${ }^{41}$ was performed with males, they also found that among the normotensive individuals, there was a more pronounced decrease in HR, showing that the vagal recovery of the hypertensive was slower.

Freitas and Santos-Júnior ${ }^{42}$ observed through an HR monitor the response of HR in 40 sedentary adults aged 20 to 39 years before and after each of the four Pilates exercises performed on the apparatus and ball. The session consisted of a single series of 10 repetitions and 2-minute intervals between exercises and found that exercise increased HR, which did not occur in our study. The increase in HR in this study may have occurred due to the insertion of ball exercises in the protocol, as it entails a higher request for balance and, consequently, greater muscle recruitment.

The reduction of the DP at 30 and 45 minutes of recovery after the exercise session may be associated with the HR response pattern. Terra et al. ${ }^{43}$ also observed a reduction of DP in hypertensive aged women after 12 weeks of strength training, with a weekly frequency of three times a week, three series of 12,10 , and 8 repetitions and intensities of $60 \%, 70 \%, 80 \%$ of $1 \mathrm{RM}$, respectively. They used the same BP measurement technique used in our study.

It was not possible to evaluate the isolated effect of the Pilates session on cardiovascular responses since hypertensives subjects were treated pharmacologically. Furthermore, the inclusion of dynamic and active stretching exercises in the protocol may also have influenced the results, although they are part of the Pilates exercise routine. Also, there was no homogeneity of the medications used by our sample, which made it impossible to investigate the interference of these variables on cardiovascular responses adequately. Another limitation was the lack of control of the participants' diet, since this factor may influence the results. The lack of ambulatory blood pressure monitoring (ABPM) was also a limiting factor since this method would allow evaluating blood pressure for a more extended period.

Despite the limitations, this study has a high practical application, seeing that the exercise protocol was based on professional practice. Besides, we sought to fill in the methodological gaps in the studies that involve the method and the cardiovascular responses regarding the training variables and intensity assessment instrument.

The results of the present study showed that performing a Pilates exercise session with one or three series does not influence the cardiovascular responses of hypertensive women since it did not evoke exacerbation in the cardiovascular responses. The results of the present study may support professional practice regarding the prescription of the series of exercises of the Pilates method during the training session for medicated hypertensive people.

\section{References}

1. Malachias MVB, Plavnik FL, Machado CA, Malta D, Scala LCN, Fuchs S. 7th Brazilian Guideline of Arterial Hypertension: Chapter 1 - Concept, Epidemiology, and Primary Prevention. Arq Bras Cardiol. 2016;107(3):1-6. doi:10.5935/abc.20160151

2. Malachias MVB, Franco RJS, Forjaz CLM, Pierin AMG, Gowdak MMG, Klein MRST, et al. 7th Brazilian Guideline of Arterial Hypertension: Chapter 6 - Non-pharmacological treatment. Arq Bras Cardiol. 2016;107(3):30-34. doi:10.5935/abc.20160156

3. Whelton PK, Carey RM, Aronow WS, CaseyJr DE, Collins KJ, Himmelfarb CD, et al. 2017 ACC/AHA/AAPA/ABC/ ACPM/AGS/APhA/ASH/ASPC/NMA/PCNA Guideline for the Prevention, Detection, Evaluation, and Management of High Blood Pressure in Adults: Executive Summary: A Report of the American College of Cardiology/American Heart Association Task Force on Clinical Practice Guidelines. Hypertens Dallas Tex 1979. 2018;71(6):1269-1324. doi:10.1161/HYP.0000000000000066

4. Arnett DK, Blumenthal RS, Albert MA, Buroker AB, Goldberger ZD, Hahn EJ, et al. 2019 ACC/AHA Guideline on the Primary Prevention of Cardiovascular Disease: Executive Summary: A Report of the American College of Cardiology/American Heart Association Task Force on Clinical Practice Guidelines. J Am Coll Cardiol. 2019;74(10):1376-1414. doi:10.1016/j.jacc.2019.03.009

5. Pescatello LS, Buchner DM, Jakicic JM, Powell KE, Kraus WE, Bloodgood B, et al. Physical Activity to Prevent and Treat Hypertension: A Systematic Review. Med Sci Sports Exerc. 2019;51(6):1314-1323. doi:10.1249/MSS.0000000000001943

6. Williams B, Mancia G, Spiering W, Rosei EA, Azizi M, Burnier $\mathrm{M}$, et al. $2018 \mathrm{ESC} / \mathrm{ESH}$ Guidelines for the management of arterial hypertension. Eur Heart J. 2018;39(33):3021-3104. doi:10.1093/ eurheartj/ehy339

7. Fleck SJ, Kraemer WJ. Fundamentos do treinamento de força muscular. 3a. Artmed; 2006.

8. Salvadeo Junior CA, Salvadeo NP de O, Conte M, Assumpção C de O. Método pilates: respostas hemodinâmicas frente a uma sessão de exercícios. Rev Bras Prescrição E Fisiol Exerc. 2016;10(61):618-627.

9. Bueno JCA, Alves RC, Smoralek AC, Souza Junior TP. Comportamento hemodinâmico e perceptual em idosas submetidas a uma sessão de diferentes protocolos do método pilates. Rev Bras Prescrição E Fisiol Exerc. 2019;13(83):481-492.

10. Wells C, Kolt GS, Bialocerkowski A. Defining Pilates exercise: a systematic review. Complement Ther Med. 2012;20(4):253-262. doi:10.1016/j.ctim.2012.02.005

11. Lima KA, Da Silva RM, Miguel dos Santos R, Leite LM, De Araújo SS. Efeitos da prática dos métodos Pilates ${ }^{\circledR}$ e musculação sobre a aptidão física e composição corporal em mulheres. Perspect Online Biológicas Saúde. 2011;1(1). doi:10.25242/8868112011514

12. Andrade LS, Mochizuki L, Pires FO, da Silva RAS, Mota YL. Application of Pilates principles increases paraspinal muscle 
activation. J Bodyw Mov Ther. 2015;19(1):62-66. doi:10.1016/j. jbmt.2014.11.011

13. Castinheiras-Neto AG, Costa-Filho IR, Farinatti PTV. Respostas cardiovasculares ao exercício resistido são afetadas pela carga e intervalos entre séries. Arq Bras Cardiol. 2010;95(4):493-501. doi:10.1590/S0066-782X2010005000119

14. Saldanha MA, Vilaça-Alves J, Neto GR, Novaes JS, Saavedra F, Reis VM, et al. Efeito do exercício resistido realizado em diferentes intensidades sobre a hemodinâmica de homens normotensos. Motricidade. 2016;12(1):60-68. doi:10.6063/motricidade.6020

15. Lemos S, Figueiredo T, Marques S, Leite T, Cardozo D, Willardson JM, et al. Effects of Strength Training Sessions Performed with Different Exercise Orders and Intervals on Blood Pressure and Heart Rate Variability. Int J Exerc Sci. 2018;11(2):55-67.

16. Junges S, Bittencourt Jacondino C, Valle Gottlieb MG. Efeito do método Pilates em fatores de risco para doenças cardiometabólicas: uma revisão sistemática. Sci Med. 2015;25(1).

17. Marinda F, Magda G, Ina S, Brandon S, Abel T, Ter Goon D. Effects of a mat pilates program on cardiometabolic parameters in elderly women. Pak J Med Sci. 2013;29(2):500-504. doi:10.12669/pjms.292.3099

18. Batista JP, Mariano IM, Souza TCF, Costa JG, Giolo JS, Cheik NC, et al. The Acute Effects of Mat Pilates on Hemodynamic and Salivary Nitrite Responses After Exercise in Postmenopausal Women. J Aging Phys Act. 2019;27(3):371-377. doi:10.1123/japa.2018-0106

19. Araujo RMA, Miguel dos Santos R, Júnior JCT, N Junior MG, Queiroz JCC, Araujo SS. O pilates reduz a pressao arterial de mulheres hipertensas. Motricidade. 2019;15(S3):171-178.

20. Rocha J, Cunha F, Cordeiro R, Monteiro W, Pescatello L, Farinatti P. Acute Effect of a Single Session of Pilates on Blood Pressure and Cardiac Autonomic Control in Middle-Aged Adults With Hypertension. J Strength Cond Res. 2020;34(1):114-123. doi:10.1519/JSC.0000000000003060

21. Martins-Meneses DT, Antunes HKM, de Oliveira NRC, Medeiros A. Mat Pilates training reduced clinical and ambulatory blood pressure in hypertensive women using antihypertensive medications. Int J Cardiol. 2015;179:262-268. doi:10.1016/j. ijcard.2014.11.064

22. Bullo V, Bergamin M, Gobbo S, Sieverdes JC, Zaccaria M, Neunhaeusereret D, al. The effects of Pilates exercise training on physical fitness and wellbeing in the elderly: A systematic review for future exercise prescription. Prev Med. 2015;75:1-11. doi:10.1016/j.ypmed.2015.03.002

23. World Health Organization (WHO). Waist Circumference and Waist-Hip Ratio : Report of a WHO Expert Consultation, Geneva, 8-11 December 2008. World Health Organization; 2011.

24. World Health Organization (WHO). Obesity: preventing and managing the global epidemic. Report of a WHO consultation. World Health Organ Tech Rep Ser. 2000;894:i-xii, 1-253.

25. Ribeiro A, Romanzini M, Nascimento M, Pina F, Souza M, Avelar A, et al. Influência da ordem de execução de exercícios com pesos sobre o volume total de treino quando a carga é ajustada de acordo com a sequência. Rev Bras Atividade Física Saúde. 2014;19(3):351-351. doi:10.12820/rbafs.v.19n3p351

26. Faria WF, Farias JP, Corrêa RC, Santos CF, Santos GC, Mendonca FR, et al. Manipulação da ordem dos exercícios não influencia o volume total durante sessão de treinamento resistido no método tri-set. Rev Bras Prescrição E Fisiol Exerc. 2019;12(79):943-952-952.

27. Robertson RJ, Goss FL, Rutkowski J, Lenz B, Dixon C, Timmer J, et al. Concurrent validation of the OMNI perceived exertion scale for resistance exercise. Med Sci Sports Exerc. 2003;35(2):333341. doi:10.1249/01.MSS.0000048831.15016.2A

28. Colado JC, Pedrosa FM, Juesas A, Gargallo P, Carrasco JJ, Flandez J, et al. Concurrent validation of the OMNI-Resistance Exercise Scale of perceived exertion with elastic bands in the elderly. Exp Gerontol. 2018;103:11-16. doi:10.1016/j. exger.2017.12.009

29. Silva RP, Novaes JS, Aquino MS, Bottaro M. Protocolos de treinamento resistido de alta velocidade de contração muscular em idosas: efeitos na percepção de esforço. J Phys Educ. 2009;20(1):77-84. doi:10.4025/reveducfis.v20i1.3506

30. Bautista IJ, Chirosa IJ, Tamayo IM, González A, Robinson JE, Chirosa LJ, et al. Predicting Power Output of Upper Body using the OMNI-RES Scale. J Hum Kinet. 2014;44:161-169. doi:10.2478/hukin-2014-0122

31. Cuckson AC, Reinders A, Shabeeh H, Shennan AH, British Hypertension Society. Validation of the Microlife BP 3BTO-A oscillometric blood pressure monitoring device according to a modified British Hypertension Society protocol. Blood Press Monit. 2002;7(6):319-324. doi:10.1097/00126097-200212000-00005

32. Scher LML, Ferriolli E, Moriguti JC, Lima NKC. Blood pressure assessed through oscillometric and auscultatory method before and after exercise in the elderly. Arq Bras Cardiol. 2010;94(5):656-662. doi:10.1590/S0066-782X2010005000031

33. Queiroz ACC, Gagliardi JFL, Forjaz CLM, Rezk CC. Clinic and ambulatory blood pressure responses after resistance exercise. J Strength Cond Res. 2009;23(2):571-578. doi:10.1519/ JSC.0b013e318196b637

34. Cunha RM, Jardim PCBV. Subacute blood pressure behavior in elderly hypertensive women after resistance exercise session. J Sports Med Phys Fitness. 2012;52(2):175-180.

35. Canuto PMBC, Nogueira IDB, Cunha ES, Ferreira GMH, Mendonca KMPP, Costa FA, et al. Influência do treinamento resistido realizado em intensidades diferentes e mesmo volume de trabalho sobre a pressão arterial de idosas hipertensas. Rev Bras Med Esporte. 2011;17(4):246-249. doi:10.1590/ S1517-86922011000400006

36. Lima T, Farinatti P, Monteiro W, Lima T, Farinatti P, Monteiro W. Effect of the number of sets on acute cardiovascular responses during stretching exercise. Rev Bras Cineantropometria Amp Desempenho Hum. 2015;17(3):291-299. doi:10.5007/1980-0037.2015v17n3p291

37. Brito AF, Oliveira CVC, Brasileiro-Santos MS, Santos AC. Resistance exercise with different volumes: blood pressure response and forearm blood flow in the hypertensive elderly. Clin Interv Aging. 2014;9:2151-2158. doi:10.2147/CIA.S53441

38. Tiggemann CL, Pinto RS, Kruel LFM. A Percepção de Esforço no Treinamento de Força. Rev Bras Med Esporte. 2010;16(4):301309. doi:10.1590/S1517-86922010000400014

39. Scher LML, Ferriolli E, Moriguti JC, Scher R, Lima NKC. The effect of different volumes of acute resistance exercise on elderly individuals with treated hypertension. J Strength Cond Res. 2011;25(4):1016-1023. doi:10.1519/JSC.0b013e3181c70b4f 
40. Mediano MFF, Paravidino V, Simão R, Pontes FL, Polito MD. Comportamento subagudo da pressão arterial após o treinamento de força em hipertensos controlados. Rev Bras Med Esporte. 2005;11(6):337-340. doi:10.1590/S1517-86922005000600006

41. Rodrigues EQ, Sousa S, Christofaro DGD, Cardoso ML, Castoldi RC, Campos EZ, et al. Cardiovascular indicators at rest, and during an incremental test in young males. Braz J Kinanthropometry Hum Perform. 2012;14(1):32-40. doi:10.5007/1980-0037.2012v14n1p32

42. Freitas CF, Santos-Júnior FFU. Análise da variação da frequência cardíaca em exercícios do método Pilates em aparelhos e na bola. Fisioter Bras. 2016;15(1):42-48. doi:10.33233/fb.v15i1.312

43. Terra DF, Mota MR, Rabelo HT, Bezerra LMA, Lima RM, Ribeiro AG, et al. Reduction of arterial pressure and double product at rest after resistance exercise training in elderly hypertensive women. Arq Bras Cardiol. 2008;91(5):299-305. doi:10.1590/ S0066-782X2008001700003

\section{Corresponding author}

Rodrigo Miguel dos Santos

Department of Circulation and Medical Imaging, St. Olavs Hospital. Prinsesse Kristinas gt. 3, 7006, Trondheim, Norway

Email: rodrigo.m.d.santos@ntnu.no

Editor: Iane de Paiva Novaes, UESB/Jequié, BA, Brazil

Manuscript received on July 15, 2019

Manuscript accepted on June 14, 2020

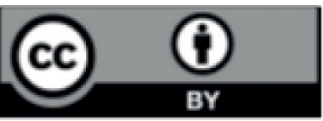

Motriz. The Journal of Physical Education. UNESP. Rio Claro, SP, Brazil - eISSN: 1980-6574 - under a license Creative Commons - Version 4.0 